\title{
Wireless Electrical Motor Parameter Monitoring System for Three Phase Induction Motor
}

\author{
Prof. Sandip R. Aher ${ }^{1}$, Manisha Khairnar ${ }^{2}$, Kaustubh Kher ${ }^{3}$, Harshda Shinde ${ }^{4}$ \\ Assistant Professor, Electrical Engineering, SSIERAS, Rahata, India ${ }^{1}$ \\ Student, Electrical Engineering, SSIERAS, Rahata, India ${ }^{2,3,4}$
}

\begin{abstract}
In the current era automation has become a basic need for the industries. Induction Machines are the nerves of many industries. Hence Industrial automation is a demand for their reliable and safe operation This paper proposes a wireless control and monitoring system for an induction motor based on serial communication protocol for safe and economic data communication in industrial fields where the wired communication is expensive or not possible due to physical conditions. A transducers and sensors monitors the parameters of induction motor and transmit the data through serial communication. A microcontroller based system is collects and stores data through computer interface developed with serial communication.
\end{abstract}

Keywords: Microcontroller, Serial \&wireless communication, Parameter monitoring, Three phase induction motor.

\section{INTRODUCTION}

Monitoring of power consumption by a micro controller or any appliance of Even plant can be monitored and stored data for the later analysis. The important parameters in power analysis are the voltage, Current, power factor, speed and winding temperature. The current is the parameter which is taken by the load in excess, in unhealthy conditions. The under voltage and over voltage conditions are also dangerous may cause the severe damage for the appliances whose voltage rating are recommended within the range of $+10 \%$ of the rated voltage. Power factor is the parameter which is harmful to Electricity Distribution Company as well as the user. In order to overcome or even to minimize the power loss the power factor should be avoided from becoming poor. Hence the power factor measurement should be first implemented. After measurement the power factor, voltage, current, speed and temperature should be sent to PC. In PC, the measured parameters are stored in the memory; with day etc. This helps in taking the parameter measurement status backup at the end of the day or even month as per the requirement, which may be helpful in further analysis. The implementation of such system requires, the voltage and current transducers, then analog signal conditioning and the microcontroller based serial communication channel for sending the data to the microcontroller.

\section{BLOCK DIAGRAM}

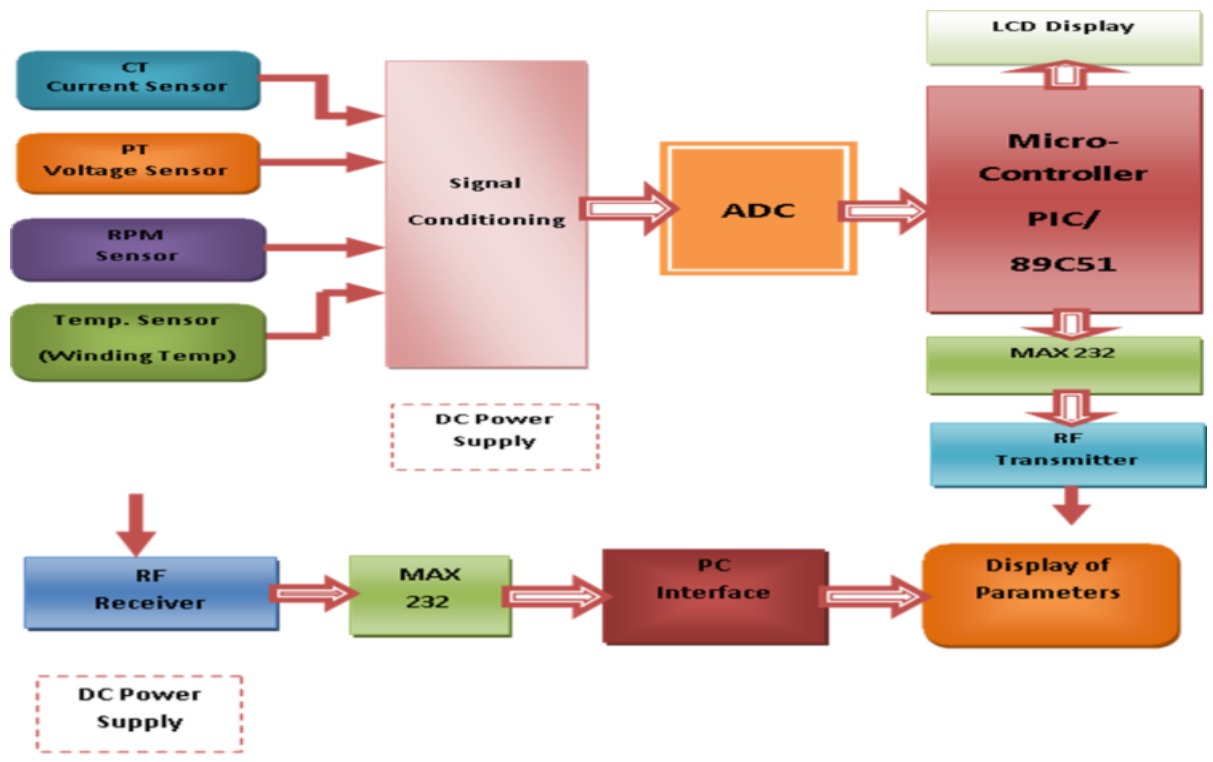

BLOCK DIAGRAM FOR WIRELESS MOTOR PARAMETER MONITORING SYSTEM 


\section{IJIREEICE \\ International Journal of Innovative Research in \\ Electrical, Electronics, Instrumentation and Control Engineering \\ ISO 3297:2007 Certified \\ Vol. 5, Issue 5, May 2017}

\section{BLOCK DIAGRAM EXPLAINATION:-}

This project is about monitoring the electrical parameters of a single phase/three phase induction motor, is basis on electrical and thermal transducers, analog signal conditioning, digital processors i.e. microcontrollers and indicating displays. In data acquisition and logging the PC interface is required. The purpose to indicate these parameter in a tubular or graphical on PC screen, the front end software is mandatory we can choose both VB or C\#. net as our front end.

Also, the interface between microcontroller and PC is wired till in the current era. But we recommend an innovative way of wireless data transfer and logging by using the RF transmitter and receiver. This function does very successfully to obtain our goals. The detail explanation of each block in this project is as below.

\section{Transducers:}

Transducer converting the physical energy into an electrical energy.In this project we have used four important parameters and their transducers.

\section{Potential transformer:}

Potential transformer is voltage transducer which senses the main AC voltage. Voltage transducer is step down the potential transformer. For $415 \mathrm{VAC}$ input, the step down output of transistor is $9 \mathrm{~V}$. it will give output $4.5 \mathrm{~V}$ for $210 \mathrm{Vac}$ input. So the potential transformer can be used for single phase and also for 3 phase applications. The potential transformer output is given to the signal conditioning block for further amplification and calibration.

\section{Current transformer}

It uses to sense the current taken by load. The current ratio is $1 \mathrm{amp}, 1 \mathrm{ma}$ and the maximum load bearing capacity is 30 amp.

For e.g. if 20 a current is passed through the conductor ten we get $20 \mathrm{ma}$ current at the secondary of the current transformer. This is AC current. A $100 \mathrm{E}, 1 / 2 \mathrm{~W}$ resistor is connected across the current transformer. The current is then given to the analog signal conditioning for further calibration purpose.

\section{PT- 100 RTD:}

The PT-100 is resistance temperature detector sensor. It uses to sense the temperature. If the temperature increases PT -100 i.e. at $0^{\circ} \mathrm{C}$ the sensor resistance is $100 \mathrm{E}$. Hence it is named as PT -100 . The resistor is connected in one of the arm of the Whetstone's meter bridge to convert into voltage. And it gives for further signal conditioning and calibration purpose.

\section{SPEED sensor}

Speed of revolution of induction machine can be measured using shaft encoder wheel and sensor.An encoder is a rotational transducer that converts angular movement into digital impulses. Speed sensor:

Different types speed measurement sensors are there. To count the events, is nothing but speed sensing. The photo electric transducer may be used for this purpose. The arrangement is as below. The rotating disc is mounted on a shaft. The rotation is sensed.

The transducer section of the project is followed by analog signal conditioning of each parameter.

\section{PIC16F877A}

40 pins multiple function 8 bits microcontroller PIC 16F877A from microchip consists simple center processing unit (CPU) of $8 \mathrm{~K}$ x 14 words of Flash program memory, $368 \times 8$ bytes of Data Memory (RAM) and $256 \times 8$ bytes of EEPROM data memory with A,B,C,D and E input/output ports provided.The function provided by this microcontroller is Timer which works as a counter, PWM module which works as controller to increase or decrease the power of any device such as motor of bulb,Synchronous (SSP) and Universal Synchronous Asynchronous Receiver Transmitter (USART/SCI) which are commonly used as the connection to computer terminal through serial port. 8channels 10 bits Analog to Digital Converter (ADC) which used to convert an analogue signal within $0-5 \mathrm{~V}$ to a binary signal 1 or 0 , Comparator provided which used to compare two inputs and output, indicate these input are same or different and etc.

The characteristic of PIC 16F877A microcontroller are:

- Low power, high speed Flash / EEPROM technology. 51

- Easy to design and reasonable price.

- Wide operating range $(2.0 \mathrm{~V}$ to $5.5 \mathrm{~V})$

- Commercial and industrial operating temperature range

\section{WORKING PRINCIPLE}

The function of the wireless data logger for monitoring of electrical parameter is illustrated in details as below. Different parameters are sensed with particular transducers and converted into voltages. The voltage from potential transformer is rectified, filtered and divided by using resistor potential divider. 


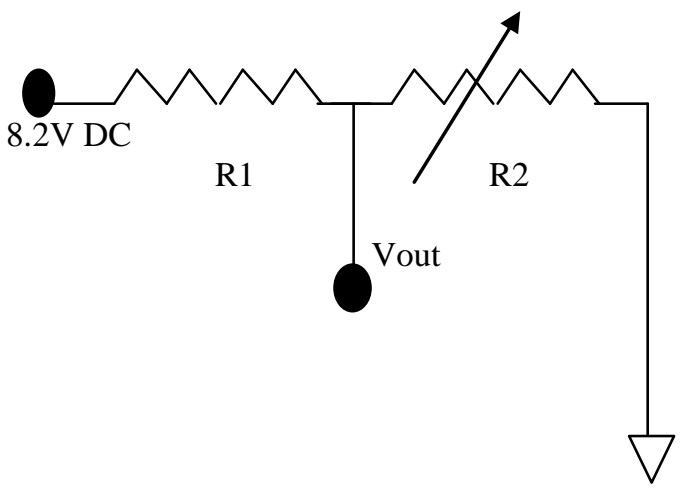

When input to potential transformer is $230 \mathrm{~V}$ AC the rectified o/p comes to be $8.2 \mathrm{~V}$. R1 and $\mathrm{R} 2$ are voltage dividing resistors. $\mathrm{R} 2$ is variable to change the $\mathrm{o} / \mathrm{p}$ if required.

$$
\text { Vout }=\left(R_{2} / R_{1}+R_{2}\right) \text { Vin }
$$

This is in milivolts, but the ADC requires $10 \mathrm{mv}$ input in order to indicate 1 unit on LCD display. So in order to indicate $230 \mathrm{~V}$ on LCD we require $2300 \mathrm{mv}$ i.e. $2.3 \mathrm{~V}$ at the input. $230 \mathrm{mv}$ is amplified by using the noninverting amplifier (ref the dia). The gain is 10 . Thus the $\mathrm{o} / \mathrm{p}$ is $2.3 \mathrm{~V}$. It varies as per the change in the input AC voltage. In similar fashion the output from current transformer is in AC voltage form.

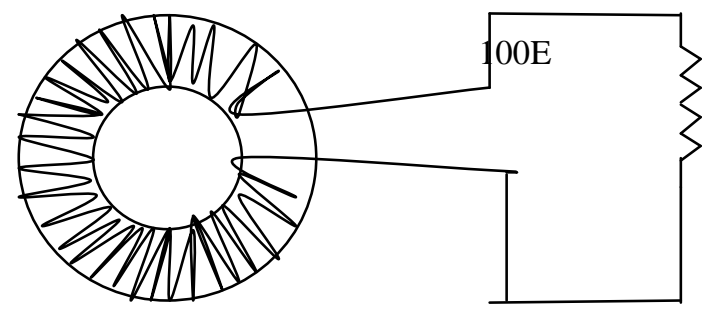

CT secondary $\mathrm{o} / \mathrm{p}$

If suppose, 20 amp current passes through the primary of the CT, the output generates 20ma. The drop across the resistor is

$$
\begin{aligned}
& =100 \mathrm{E} \times 20 \mathrm{ma} \\
& =100 \mathrm{E} \times .02 \mathrm{~A} \\
& =2 \mathrm{~V}
\end{aligned}
$$

This AC voltage is given to precision rectifier for rectification purpose. The purpose of using the precision rectifier is to rectify the voltage below $0.7 \mathrm{~V}$ also. As the current may be in milliampere. The output of precision rectifier is DC. This is given to ADC through mux. Here also, calibration is done in order to get required voltage at the output.

\section{ADVANTAGES}

1. No wiring cost and maintenance

2. Range can be increased upto 100 meters and more with adequate RF modules.

3. Data logging provides the off line services also previous data can be observed on pc as and when required.

4. Data observed on PC and LCD locally

5. This type of communication can done free of cost.

\section{DISADVANTAGES}

1. The RF modems are antistatic.

2. These type of communication can be failed if the communication protocols are not followed.

\section{CONCLUSION}

The parameter monitoring system in this project is a combination of advanced techniques and plant management process, aiming for goal through technical means. Wireless sensor network is used to transmit datas collected from the 


\section{IJIREEICE \\ International Journal of Innovative Research in \\ Electrical, Electronics, Instrumentation and Control Engineering \\ ISO 3297:2007 Certified \\ Vol. 5, Issue 5, May 2017}

machine to the base station. Embedded $\mathrm{C}$ is used for the graphical user interface. Embedded $\mathrm{C}$ programming language is used to program the microcontroller. The total system gives an current, voltage. speed, winding temperature and power factor measurement of the parameters of the induction motor.

\section{ACKNOWLEDGEMENT}

We take immense pleasure to express our profound gratitude and heartful thanks to Prof. Sandip R. Aher. Professor, SSIERAS, Rahata. for his exemplary guidance, monitoring and constant encouragement throughout the completion of our final year B.E project. The blessings, help and guidance given by him from time to time shall carry us a long way in the journey of life on which we are about to embark.

We also express a deep sense of gratitude to thank Dr. Y.R. Kharde Principal ,SSIERAS Rahata for providing well organised infrastructure being helpful in completion of our project.

\section{REFERRENCES}

[1] B. Lu, T. G. Habetler, and R. G. Harley, -A nonintrusive and in-service motor-efficiency estimation method using air-gap torque with considerationsof condition monitoring,\| IEEE Trans. Ind. Appl., vol. 44, no. 6,pp. 1666-1674, Nov./Dec. 2008.

[2] J. Pedro Amaro †, Fernando J.T.E. Ferreira,\|low cost wireless sensor for in field monitoring of induction motorl, , „IEEE Trans. Ind. Appl., vol. 44, no. 6,pp. 1666-1674, Nov./Dec. 2010.

[3] Yanfeng Li 1,2, Haibin Yu,lenergy management of induction motors based on non-intrusive efficiency estimationl, Proceeding of International Conference on Electrical Machines and Systems 2007.

[4] Nagendrappa. H1 , Prakash Bure2, lenergy audit and management of induction motor using genetic algorithmll International Journal of Recent Trends in Engineering

[5] V.P. Sakthivel1 R. Bhuvaneswari2 S. Subramanian,\| Non-intrusive efficiency estimation method for energy auditing and management of inservice induction motor using bacterial foraging algorithm\| Published in IET Electric Power Applications Received on 28th December 2009 Revised on 23rd March 2010 doi: 10.1049/iet-epa.2009.0313

[6] Abel C. Lima-Filho - Embedded system integrated into a wireless sensor network for online dynamic torque and efficiency monitoring in induction motors\| Ieee/asme transactions on mechatronics, vol. 17, no. 3, june 2012

[7] T. Phumiphak, and C. Chat-uthai,\|An Economical Method for Induction Motor Field Efficiency Estimation for Use in On-site Energy Audit and Management\| 2004 lntematlonal Conference on Power System 2004

[8] R. Hanitsch, -Energy Efficient Electric Motors, \| in Proc. RIO 02-World Climate Energy Event, 2002, pp. 6-11. 